Article

\title{
Sustainability of Government Social Media: A Multi-Analytic Approach to Predict Citizens' Mobile Government Microblog Continuance
}

\author{
Shuiqing Yang * and Xianwu Zeng \\ Department of Information Management and Engineering, Zhejiang University of Finance \& Economics, \\ Hangzhou 310018, China; zengxianwu87@126.com \\ * Correspondence: d200877707@hust.edu.cn
}

Received: 5 November 2018; Accepted: 13 December 2018; Published: 19 December 2018

\begin{abstract}
Attracting citizens and facilitating their continued usage is critical for the sustainable development of mobile government microblog services. Drawing on the stimulus-organism-response (SOR) framework and the literature related to perceived value, this study investigates the factors that affect citizens' continuance intention vis-a-vis mobile government microblogs from a value-based perspective. A structural equation modeling (SEM)-neural network combined method was used to test the proposed model by using data collected from 301 mobile government microblog users in China. The SEM analysis shows that social influence, perceived interactivity, and perceived mobility positively affect citizens' utilitarian value and hedonic value, which further affects their continuance intention. The significant factors obtained from the SEM are used as input for a neural network analysis to calculate their relative impacts. The results of the neural network analysis showed that perceived mobility is the most important factor influencing utilitarian value, while social influence is the most significant factor affecting hedonic value. The normalized importance of utilitarian value on continuance behaviors is larger than that of hedonic value.
\end{abstract}

Keywords: social media; government microblog; continuance intention; perceived value; neural network

\section{Introduction}

Microblogs, with the functionalities of information broadcast, social interaction, and relationship building, have been embraced by government agencies and officials worldwide [1]. According to the 42nd China Internet Development Statistics Report, the number of government microblogs on Sina Weibo had reached 137,000 by the end of June 2018 [2]. Government microblogs are usually registered and operated on third-party microblogging platforms such as Sina Weibo and Twitter [1]. In fact, microblogs can be regarded as a hybrid of instant messaging and blog, which allows users to broadcast short messages about their experiences in daily life [3]. Specifically, with the recent advancement of wireless communication technologies, mobile government microblogs have become an important communication platform to facilitate two-way interactions between government agencies and citizens [4]. In this study, mobile government microblog refers to a microblog managed by government agencies or officials on the Sina Weibo mobile microblog platform. As the largest social media platform in China, Sina Weibo has invited a large number of government offices and departments to open microblog accounts [2]. Government offices and departments use their accounts to release or obtain information, and to interact with citizens. By offering ubiquitous, location-based, and personalized services to citizens, mobile government microblogs create new opportunities for government-citizen relationship building [4], providing public services [5], public engagement [6], 
and the monitoring of government corruption [7]. Many government microblog managers believe that due to its ability to provide information and interactive services anytime and anywhere, citizens will be readily attracted by mobile government microblogs. However, retaining existing users and encouraging their continued use is always not easy. The rate of citizens' continuous usage of mobile government microblog is still low. Therefore, it is important to explore the factors that determine citizens' mobile government microblog continuance behaviors, and thus, the sustainability of mobile government microblogs.

Many studies have tried to explain mobile microblog usage by using the leading technology acceptance model or its extension [8,9]. The process which underlies citizens' continuous usage of mobile government microblogs has seldom been explored. The present study therefore adopted the stimulus-organism-response (SOR) framework [10] to investigate citizens' continuance of mobile government microblogs by focusing on the stimuli from social influence and media characteristics on their value perceptions. Specifically, this study examines (1) How the mobile government microblogs stimulate citizens (i.e., social influence, perceived mobility, and perceived interactivity), influencing their reactions (i.e., perceived value), and subsequently affecting their coping responses (i.e., continuance intention of using mobile government microblogs). (2) What are the different roles of perceived hedonic value and perceived utilitarian value on citizens' evaluations of mobile government microblogs, and what subsequently shaped their continuance intentions?

The present study contributes to the existing literature in two ways. First, despite the fact that a lot of prior studies were devoted to understanding mobile microblog usage behavior, the underlying mechanisms of how and why citizens actively continue to use mobile government microblogs remain unknown. The present study thus applied the SOR framework to a mobile government microblog context and explored social influences and media characteristics on citizens' continuous usage. In particular, unlike extant studies which mainly focused on utilitarian value to explain mobile microblog usage, our study explores citizens' mobile government microblog continuance by considering both utilitarian and hedonic value. Second, unlike the extant literature that mainly utilized linear models (e.g., structural equation modeling, SEM) to explain mobile microblog usage [4], the present study employed a two-staged SEM-neural network approach to predict mobile government microblog continuance behavior [11-13]. The SEM method is primarily designed for theory validating and linear relationships modeling analysis, while it usually oversimplifies the process of users' decisions making in terms of the use of a specific information system [11]. This disadvantage can be addressed by using a neural network modelling approach which can detect both linear and complex non-linear relationships between variables $[12,14]$. But because of its black box characteristics, the neural network method is unsuitable for validating theories [11,12]. Therefore, the combination of SEM and neural network modelling can make use of the advantages of each of the two approaches [15]. The present study provides not only a theoretical understanding of citizens' mobile government microblog usage behavior, but also presents practical insights for government agencies and officials for increasing the sustainability of mobile government microblog services.

This paper is organized as follows. The research background and theoretical foundation are presented in the next section. In the third section, the research model and hypotheses are presented, followed by a description of the research methodology and an analysis of the data. Finally, this study concludes by summarizing the findings and the theoretical and practical implications as well as limitations.

\section{Background and Theoretical Foundation}

\subsection{Research Background}

Mobile Government Microblog in China

China, as a rapidly-growing economy [16], is attracting more and more attention from both academia and industry across the globe [17]. As a new media form of communication and dissemination, government microblogs have played an important role in linking the Chinese government and the 
citizens [18]. Premier Li, in the 2015 Chinese government work report, expressed a desire "to continue making government affairs more transparent and developing e-government and online office" [8]. The need to make government organizations more sustainable and greener has become a consensus in the modern society [19]. Sustainability can be described through four spheres, i.e., social, economics, politics, and culture [20]. In the political or government domain, the development of Internet-based communication technologies such as mobile social media is one of the most important metrics and indices for building sustainable and green e-government organizations [20]. In recent years, government agencies at all levels have launched their own official microblogs (e.g., Beijing release, Shanghai release), which are intended to meet the sustainable development needs of e-government.

Microblog, usually referred to as the "Chinese Twitter", is one of the most popular social network services in China, with 337.4 million active users at the end of June 2018 [2]. It is worth noting that 315.5 million active users access the microblog platform through mobile devices, accounting for 93.5 percent of the total number of users [2]. Indeed, nowadays, with the increasing popularity of mobile smart devices in China, more and more citizens are accessing the government microblog through their mobile devices. The mobile government microblog has become a new platform for Chinese government agencies to strengthen communication with the people and further improve the relationship between the government and the public.

\subsection{Theoretical Foundation}

\subsubsection{The Stimulus-Organism-Response (SOR) Framework}

In the field of microblog usage, several theories were employed to explicate citizens' intention to use the microblog [8,21]. Among them, Kim, Lee and Son [21] employed social influence theory to study citizens' intention to use the microblog. The result of this study showed that social influence factors including social identity, group norms, and social presence positively affect continuous use intention. Jiang, Zhao, Sun, Zhang, Zheng and Qu [8] extended the theory of planned behavior (TPB) to predict the intention to use the microblog. They found that three motivational factors, i.e., attitude, subjective norms, and perceived behavioral control, significantly affect behavioral intention, which in turn determines personal microblog usage behavior [8]. In prior studies, the theory of planned behavior explains behaviors mainly focusing on individual attitudes, which neglects social influence, a critical factor of technology adoption and diffusion in the social context [22]. The stimulus-organism-response (SOR) framework [10] provides a useful theoretical foundation for understanding the underlying decision making process of citizens' mobile government microblog continuance usage.

Originating from the domain of environmental psychology, the SOR model's logical assumption is that external environmental cues act as stimuli (S) and affect individuals' emotional or cognitive responses $(\mathrm{O})$, which further invoke their behavioral responses $(\mathrm{R})[4,10,23]$. This framework is extensively used by scholars to explore the relationship between external environmental stimuli and behavioral intentions, providing a good configuration scheme of environment variables. For example, Guo, Liu and Liu [4] draw upon the SOR framework to develop a model for identifying the key success factors for launching government social media platforms. Based on the SOR framework, Islam and Rahman [23] found that the stimuli reflected by the online communities' unique features positively influence members' engagement and subsequent loyalty.

In the present study, the SOR framework is also adopted as the foundation of our research in explaining citizens' mobile government microblog continuance behavior [10]. The reasons for employing the SOR framework in our study are as follows. First, the environmental stimuli were measured based on two aspects, namely, sociality and media characteristics. Second, the internal organism states were measured as perceived value, which was conceptualized as a second-order variable by including two first-order variables: hedonic value and utilitarian value. Third, the behavioral response was measured as continuance intention of using the mobile government microblog. 


\subsubsection{Utilitarian Value and Hedonic Value}

Babin, et al. [24] classified perceived value into two different types, namely hedonic and utilitarian value. Utilitarian value is defined as an overall judgment of functional benefits and sacrifices [25]. From the utilitarian point of view, citizens are very task-oriented and rational when there is a certain behavioral intention [26]. Compared with utilitarian value, hedonic value is more subjective and personal [27]. From the perspective of hedonic value, citizens desire entertainment and consider the using process as a joyful experience [28]. The positive effects of both hedonic and utilitarian value on user behaviors have been validated in a mobile social media context [27]. Therefore, to fully capture the value perceptions in the mobile social media context, the present study included both perceived utilitarian value and perceived hedonic value to understand mobile government microblog continuance behavior.

\section{Research Model and Hypotheses}

In the present study, the stimulus-organism-response (SOR) framework was employed as the theoretical foundation of the research to explain how external environmental stimuli will influence citizens' organism experiences, and in turn, further affect their response to mobile government microblog continuance usage [29]. Figure 1 shows the research model and the hypothesized relationships.

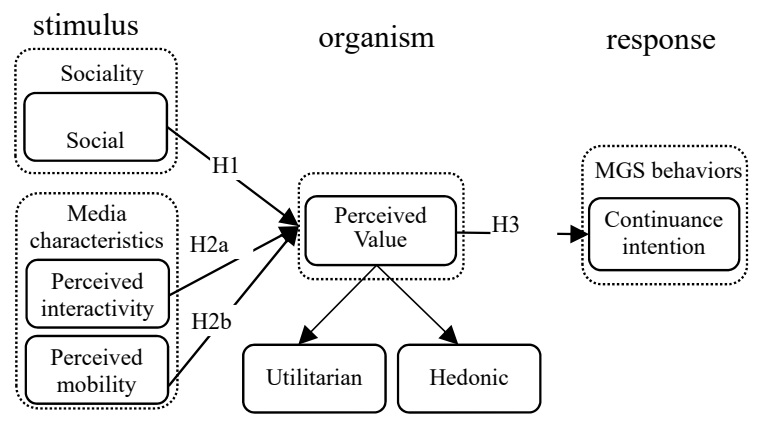

Figure 1. Research model.

\subsection{Sociality}

Social Influence

Social influence is defined as the pressure that a person perceived from her or his social networks [30]. Social influence has long been validated as a critical factor in explaining adoption behavior in the innovation diffusion literature [31]. Recently, in the context of mobile technology-based services, a number of studies incorporated social influence into their research and found some empirical support [32]. For example, Hong and Tam [33] found that social influence affects mobile data services usage intention directly and indirectly through perceived usefulness.

In the context of our study, as an effective social media platform, the mobile government microblog can allow citizens to easily interact with their relatives, schoolmates, and friends [4]. When citizens find some interesting information or useful services on the mobile government microblog platform, they can share it with their relatives and friends. Therefore, during the interaction, it is expected that the influence of citizens' social connections will positively affect their value perceptions of using the mobile government microblog. Based on the existing literature [33], we therefore hypothesize:

H1. Social influence will positively affect perceived value.

\subsection{Media Characteristics}

\subsubsection{Perceived Interactivity}

Perceived interactivity is defined as "the extent to which users perceive their experiences as a simulation of interpersonal interaction and sense they are in the presence of a social other" [34,35]. 
Research on mobile users' online experiences has revealed that improved interactivity is positively related to user satisfaction [36].

Zhao and $\mathrm{Lu}$ [3] examined interactivity from four dimensions: control, connectedness, playfulness, and responsiveness. The dimension of playfulness emphasizes the enjoyment and happiness individuals derive from being involved in an activity. The previous study showed that perceived enjoyment allows users to experience a greater hedonic value [37]. Through the two-way interactions between the government agencies and its citizens, citizens can get more useful government information. We might expect that, when citizens are using the mobile government microblog services, perceived interactivity could bring them not only hedonic value, but also utilitarian value. We thus hypothesized:

H2a. Perceived interactivity will positively affect perceived value.

\subsubsection{Perceived Mobility}

Based on existing studies [38], perceived mobility is defined as a citizen's perception of the time and place required to use the mobile government microblog. In the context of online citizen behavior, perceived mobility has been proved to be an important factor in citizens' decisions to choose online channels for virtual communications rather than face to face interactions [39]. Venkatesh et al. [40] also found that channel characteristics including convenience positively affect citizens' intentions to use e-government.

In the context of the present study, citizens can access the government microblog anytime and anywhere through mobile devices [41]. The mobility feature of the mobile government microblog helps citizens receive public information and services in a convenient manner, which in turn enhances citizens' value perceptions. Based on the current studies [38,40], we can hypothesize:

H2b. Perceived mobility will positively affect perceived value.

\subsubsection{Perceived Value}

Existing research reported that both utilitarian and hedonic value have a positive impact on online users' continued usage intentions [18]. In the mobile services context, previous research also found that when citizens perceive high levels of utilitarian and hedonic value from using mobile services, they will be more likely to develop high levels of satisfaction and continuance intention [37,39]. For instance, Kim, et al. [42] proposed a mobile user engagement (MoEN) model and applied it to exploring mobile user continued engagement intention from the perspective of user's motivation and perceived value. The results revealed a positive connection between perceived value and users' continued smart phones engagement. In our study, it is expected that perceived value will exert an important influence on citizen's mobile government microblog continuance intention. Based on the existing studies [42], we can propose that:

H3. Perceived value will positively affect citizen's continuance intention of using mobile government microblog.

\section{Methodology}

\subsection{Instrument}

The research model includes five constructs. To guarantee the validity of the whole instrument, every construct was measured with multiple items which were all adapted from previous research, but were modified to fit our context. We used 7-point Likert scales in the questionnaire, with response selections ranging from one (strongly disagree) to seven (strongly agree). Four items on social influence were adapted from $\mathrm{Lu}$, et al. [43] to measure the impact of social image and subjective norms on the continuance usage of the mobile government microblog. Three items on perceived interactivity were adapted from Wang and Wang [44]. They reflect the communication between mobile government microblog users and other users on time, frequency, and relationships. We adapt the items for perceived mobility from Venkatesh, Thong, Chan and $\mathrm{Hu}$ [40] to assess the convenience and timeliness of using 
the mobile government microblog. Perceived value includes two dimensions: hedonic value and utilitarian value. Three items on hedonic value were adapted from Kim and Han [45] to measure the happiness of mobile government microblog users, and two items on utilitarian value were adapted from Kim and Han [45] to measure the benefits of mobile government microblog users. Three items on continuance intention were adapted from Zhao and $\mathrm{Lu}$ [3], Venkatesh, Thong, Chan and $\mathrm{Hu}$ [40], and measured the continuous intention to use the mobile government microblog. A back-translation procedure was performed to ensure the validity of the translation. The final items are listed in Appendix A.

\subsection{Sample}

Empirical data were collected through an online survey which hosted by a professional survey website platform (www.sojump.com). Sojump.com has over 1 million active users out of its 2.6 million registered users. The Sina government microblog service was chosen as our research focus as it is one of China's largest microblog platforms.

The payment data collection services provided by sojump.com was used for the sample collection in our study. The object of our study is to examine mobile government microblog continuance behavior; participants must therefore have certain experience of using the mobile government microblog. Sojump.com was responsible for issuing the questionnaire to qualified respondents. The sample collection procedure took two weeks. Finally, 301 validated responses were collected after dropping some invalid responses, i.e., from those without mobile government microblog usage experience. Table 1 shows the sample demographics. According to the report of the respondents, about $48.2 \%$ were male. Most of the respondents were between the ages of 18 and 35. For most people, microblog services are primarily available through smart phones, which are mainly used by the younger generation. Obviously, the younger individuals are more interested in exploring this popular service using their mobile smart devices.

Table 1. Demographics of the research sample.

\begin{tabular}{clll}
\hline Measure & Item & Count & Percentage (\%) \\
\hline \multirow{2}{*}{ Gender } & Male & 145 & 48.2 \\
& Female & 156 & 51.8 \\
\hline \multirow{2}{*}{ Age } & 18 or below & 2 & 0.7 \\
(years old) & $>18$ and $\leq 25$ & 73 & 24.3 \\
& $>26$ and $\leq 35$ & 179 & 59.5 \\
& 35 or above & 47 & 15.6 \\
\hline \multirow{3}{*}{ Education } & High school or below & 18 & 6.0 \\
& Junior college & 74 & 24.6 \\
& Undergraduate & 181 & 60.1 \\
& Master & 21 & 7.0 \\
& Doctor or above & 7 & 2.2 \\
\hline & Worker & 118 & 39.2 \\
& Manager & 59 & 19.6 \\
& Teacher & 33 & 11.0 \\
& Doctor & 9 & 3.0 \\
& Freelancer & 23 & 7.6 \\
& Student & 30 & 10.0 \\
& Civil servant & 19 & 6.3 \\
& Self - employed & 5 & 1.7 \\
& Others & 5 & 1.7 \\
\hline
\end{tabular}


Table 1. Cont.

\begin{tabular}{clll}
\hline Measure & Item & Count & Percentage (\%) \\
\hline & $\leq 1$ & 44 & 14.6 \\
Use mobile microblog & $>1$ and $\leq 3$ & 113 & 37.5 \\
experience (year) & $>$ 3and $\leq 5$ & 99 & 32.9 \\
& $>5$ & 45 & 15.0 \\
\hline Total & & 301 & 100 \\
\hline
\end{tabular}

\section{Data Analysis and Results}

\subsection{Assessment of the Measurement Model}

We employed the two-step structural equation modeling analysis method recommended by Anderson and Gerbing [46] to examine the measurement and structural model. Cronbach's alpha (CA) and composite reliability (CR) were adopted to test the internal reliability of the instruments. As showed in Table 2, CA and CR coefficients were all above 0.8 , suggesting adequate internal consistency.

Table 2. Scale properties.

\begin{tabular}{cccccc}
\hline Factor & Item & Loading & CA & CR & AVE \\
\hline \multirow{4}{*}{ SOI } & SOI1 & 0.872 & & & \\
& SOI2 & 0.859 & 0.887 & 0.922 & 0.746 \\
& SOI3 & 0.868 & & & \\
& SOI4 & 0.856 & & & \\
\hline \multirow{3}{*}{ PEI } & PEI1 & 0.869 & & & \\
& PEI2 & 0.892 & 0.850 & 0.909 & 0.769 \\
& PEI3 & 0.870 & & & \\
\hline \multirow{3}{*}{ PEM } & PEM1 & 0.898 & & & \\
& PEM2 & 0.876 & 0.868 & 0.917 & 0.786 \\
& PEM3 & 0.885 & & & \\
\hline \multirow{3}{*}{ HEV } & HEV1 & 0.907 & & & \\
& HEV2 & 0.913 & 0.896 & 0.935 & 0.827 \\
& HEV3 & 0.908 & & & \\
\hline \multirow{2}{*}{ UTV } & UTV1 & 0.919 & \multirow{2}{*}{0.829} & 0.921 & 0.854 \\
& UTV2 & 0.929 & & & \\
\hline \multirow{2}{*}{ COI } & COI1 & 0.886 & & & \\
& COI2 & 0.854 & 0.844 & 0.906 & 0.762 \\
& COI3 & 0.879 & & & \\
\hline
\end{tabular}

* SOI = Social influence; $\mathrm{PEI}=$ perceived interactivity; $\mathrm{PEM}=$ perceived mobility; $\mathrm{HEV}=$ Hedonic value; $\mathrm{UTV}=$ Utilitarian value; $\mathrm{COI}=$ Continuance intention

A confirmatory factor analysis (CFA) was also conducted to examine the instrument validity. Table 2 displays the standardized loadings and average variance extracted (AVE). As shown in Table 2, all loadings were greater than 0.6, and all the AVE values were higher than 0.7, indicating good convergent validity [47].

The discriminant validity was measured by comparing the square root of AVE and the inter construct correlations. As shown in Table 3, all construct square roots of AVEs were higher than their corresponding inter-construct correlations coefficients, suggesting good discriminant validity. 
Table 3. Inter-construct correlations.

\begin{tabular}{lllllll}
\hline & HEV & UTV & COI & PEI & PEM & SOI \\
\hline HEV & $\mathbf{0 . 9 0 9}$ & & & & & \\
UTV & 0.614 & $\mathbf{0 . 9 2 4}$ & & & & \\
COI & 0.653 & 0.693 & $\mathbf{0 . 8 7 3}$ & & & \\
PEI & 0.653 & 0.591 & 0.683 & $\mathbf{0 . 8 7 7}$ & & \\
PEM & 0.607 & 0.662 & 0.683 & 0.570 & $\mathbf{0 . 8 8 6}$ & \\
SOI & 0.695 & 0.558 & 0.569 & 0.668 & 0.456 & $\mathbf{0 . 8 6 4}$ \\
\hline
\end{tabular}

Notes: The bold numbers are the square root of the AVEs. Diagonal elements are the square roots of the AVEs. These values should exceed the inter-construct correlations for adequate discriminant validity. SOI = Social influence; $\mathrm{PEI}=$ perceived interactivity $; \mathrm{PEM}=$ perceived mobility $; \mathrm{HEV}=$ Hedonic value; $\mathrm{UTV}=$ Utilitarian value $\mathrm{COI}=$ Continuance intention.

An exploratory factor analysis (EFA) was conducted to further examine the discriminant validity of the scales. As shown in Table 4, the internal loading of every distinct factor was higher than the cross-loadings on other factors, suggesting good discriminant validity.

Table 4. Results of factor analysis with overall sample.

\begin{tabular}{ccccccc}
\hline Factors & SOI & PEI & PEM & HEV & UTV & COI \\
\hline SOI1 & 0.767 & 0.172 & 0.140 & 0.235 & 0.077 & 0.302 \\
SOI2 & 0.804 & 0.144 & 0.176 & 0.184 & 0.058 & 0.231 \\
SOI3 & 0.802 & 0.243 & 0.154 & 0.199 & 0.167 & 0.100 \\
SOI4 & 0.655 & 0.315 & 0.029 & 0.339 & 0.308 & 0.090 \\
PEI1 & 0.141 & 0.708 & 0.383 & 0.261 & 0.126 & 0.219 \\
PEI2 & 0.339 & 0.739 & 0.201 & 0.141 & 0.089 & 0.267 \\
PEI3 & 0.386 & 0.704 & 0.057 & 0.225 & 0.188 & 0.228 \\
PEM1 & 0.189 & 0.262 & 0.783 & 0.141 & 0.162 & 0.220 \\
PEM2 & 0.077 & 0.112 & 0.793 & 0.194 & 0.165 & 0.250 \\
PEM3 & 0.162 & 0.117 & 0.772 & 0.242 & 0.188 & 0.210 \\
HEV1 & 0.320 & 0.232 & 0.211 & 0.743 & 0.200 & 0.175 \\
HEV2 & 0.353 & 0.128 & 0.240 & 0.728 & 0.198 & 0.259 \\
HEV3 & 0.268 & 0.258 & 0.292 & 0.755 & 0.059 & 0.215 \\
UTV1 & 0.246 & 0.155 & 0.304 & 0.169 & 0.795 & 0.226 \\
UTV2 & 0.182 & 0.203 & 0.357 & 0.238 & 0.632 & 0.388 \\
COI1 & 0.246 & 0.151 & 0.332 & 0.207 & 0.196 & 0.717 \\
COI2 & 0.146 & 0.286 & 0.264 & 0.153 & 0.221 & 0.706 \\
COI3 & 0.188 & 0.294 & 0.274 & 0.280 & 0.144 & 0.669 \\
\hline
\end{tabular}

* SOI = Social influence; $\mathrm{PEI}$ = perceived interactivity; $\mathrm{PEM}=$ perceived mobility; $\mathrm{HEV}=$ Hedonic value; $\mathrm{UTV}=$ Utilitarian value; $\mathrm{COI}=$ Continuance intention .

\subsection{Assessment of the Structural Model}

In the present study, the research model was tested by a component-based SEM method which has been widely adopted in the literature. Compared with covariance-based structural equation modeling (CB-SEM) methods, the component-based SEM method (e.g., SmartPLS 2.0) can handle both reflective and formative constructs. In addition, it can also analyze the second-order constructs model. In our study, perceived value is conceptualized as a second-order construct which includes both perceived utilitarian value and perceived hedonic value. Therefore, Partial least squares (SmartPLS 2.0) was used to test the research model and the corresponding hypotheses. The PLS results of the research model, including the path coefficients, significance, and variance (R2), are shown in Figure 2. The results showed that all hypothesized paths were supported by the empirical data. The hypothesized paths from social influence, perceived interactivity, and perceived mobility on perceived value were all significant, supporting hypotheses $\mathrm{H} 1, \mathrm{H} 2 \mathrm{a}, \mathrm{H} 2 \mathrm{~b}$. The hypothesized paths from perceived value on continuance usage were also significant, validating hypotheses $\mathrm{H} 3$. 


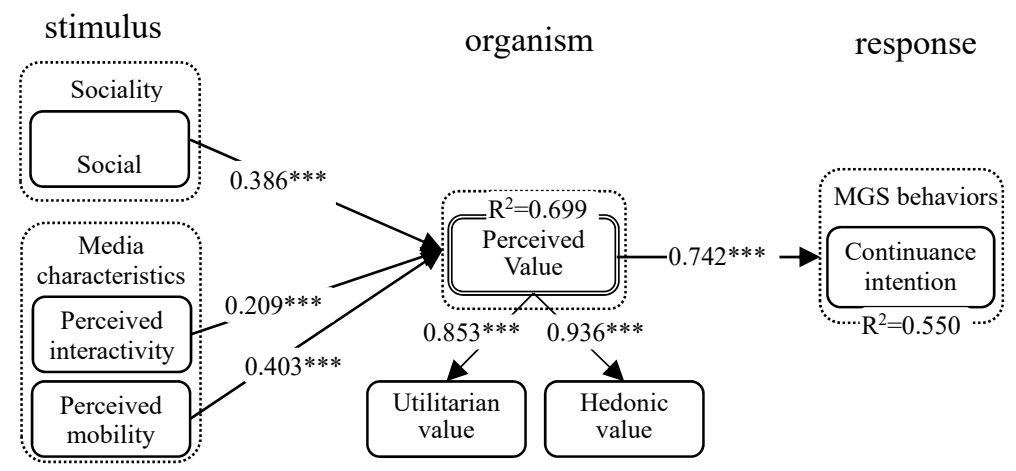

Figure 2. Result of the model tests (second-order construct). Note: ${ }^{* * *} p<0.001$.

The model showed $55.0 \%$ variance in continuance intention of using mobile government microblog, and $69.9 \%$ of the variance in perceived value. It suggests that the model provided a reasonable explanation of the variance in citizens' perceived value in the mobile government microblog services and their continuous intention to use the mobile government microblog.

To further test the different impacts of citizens' utilitarian value and hedonic value perceptions on mobile government microblog continuance behaviors, we decompose the second-order variables into two first-order variables. As shown in Figure 3, the impacts of social influence, perceived interactivity, and perceived mobility on both perceived utilitarian value and hedonic value were all significant, which further affects continuance intention of using the mobile government microblog. In terms of the path coefficient and significance levels, perceived mobility exerts the strongest influence on utilitarian value perceptions, followed by social influence and perceived interactivity, while social influence exerts the strongest impact on hedonic value perceptions, followed by perceived mobility and perceived interactivity. In addition, utilitarian value exerts more influence on mobile government microblog continuance behavior than hedonic value in terms of the path coefficient and significant levels.

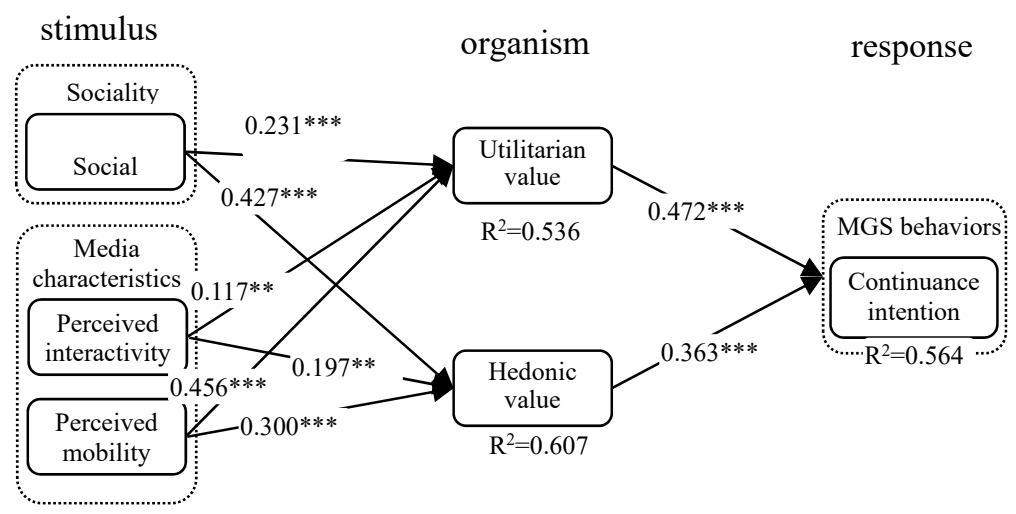

Figure 3. Result of the model tests. Note: ${ }^{* *} p<0.01$; ${ }^{* * *} p<0.001$.

\subsection{Neural Network Analysis}

A neural network model connects input and output systems through neurons and can simulate the nervous system of the human brain for complex information processing, and has memory and continuous learning capabilities [12]. Neural network analysis can not only detect linear relationships, but can also identify non-linear relationships [15]. At the same time, neural networks can learn and tolerate noise samples through the training process [12]. Therefore, neural network analysis can be combined with structural equation modeling method to better explain and predict user behavior.

Following the procedures conducted by previous studies [12,14], a multi-layer perceptron is adopted to establish the neural network model by using SPSS 20.0. The input variables of the neural network model are the significant variables obtained from the structural equation model. Three neural network models were developed to predict the factors that affect mobile government microblog 
continuance behaviors. Specifically, as displayed in Table 5, the input neurons of Model 1 are social influence, perceived interactivity and perceived mobility, and its output neuron is utilitarian value. The input neurons of Model 2 are social influence, perceived interactivity, and perceived mobility, and its output neuron is hedonic value. The input neurons of Model 3 are utilitarian value and hedonic value, and its output neuron is continuance intention.

Table 5. RMSE Values for ANN Model 1 and 2.

\begin{tabular}{ccccc}
\hline & $\begin{array}{c}\text { Model 1 Input neuron: SOI, PEI, PEM } \\
\text { Output neuron: UTV }\end{array}$ & $\begin{array}{c}\text { Model 2 Input neuron: SOI, PEI, PEM } \\
\text { Output neuron: HEV }\end{array}$ \\
\hline Network & Training & Testing & Training & Testing \\
1 & 0.2018 & 0.2082 & 0.1960 & 0.1899 \\
2 & 0.1994 & 0.2039 & 0.1925 & 0.1988 \\
3 & 0.2097 & 0.2088 & 0.1942 & 0.2009 \\
4 & 0.2019 & 0.2097 & 0.1930 & 0.2007 \\
5 & 0.2013 & 0.2088 & 0.1931 & 0.2014 \\
6 & 0.2073 & 0.2046 & 0.1951 & 0.2034 \\
7 & 0.2015 & 0.2072 & 0.1856 & 0.1948 \\
8 & 0.1989 & 0.2018 & 0.1939 & 0.1887 \\
9 & 0.1957 & 0.1913 & 0.1955 & 0.1984 \\
10 & 0.2125 & 0.2115 & 0.1785 & 0.1823 \\
Mean & 0.2030 & 0.2056 & 0.1917 & 0.1959 \\
Standard & 0.0049 & 0.0055 & 0.0052 & 0.0065 \\
deviation & & & & \\
\hline
\end{tabular}

* SOI = Social influence; PEI = perceived interactivity; PEM = perceived mobility; HEV = Hedonic value; UTV=Utilitarian value.

As no heuristic method for identifying the number of the hidden nodes in a neural network exists, our study examined the neural network by using one to ten hidden nodes, which is consistent with the procedure conducted by [15]. To avoid over-fitting, this study conducted ten-fold cross-validation, whereby $90 \%$ of the data was used for network training, and the remaining $10 \%$ was used for testing, i.e. measuring the accuracy of the trained network's predictions [11,12].

The root mean squared error (RMSE) of the training and testing datasets for all ten neural networks and the mean and standard deviation of the two datasets were used to measure the model's prediction accuracy. Tables 5 and 6 show the root mean squared error and its mean of the training and testing data for the ten neural networks, as well as the standard deviation values. As displayed in the tables, the average root mean square error of the neural network model is small (training data is 0.2030, 0.1917 , and 0.2029 respectively, test data is $0.2056,0.1959$ and 0.2030 respectively), which indicates that the neural network model has higher credibility and can accurately predict the relationship between variables and output [12].

The normalized importance is the ratio of the importance of each predictor variable to the highest importance value. Tables 7 and 8 show the results of the sensitivity analysis. As displayed in Table 7, the normalized importance of social influence, perceived interactivity, and perceived mobility to utilitarian value is $90.2 \%, 94.9 \%$, and $100 \%$ respectively. The normalized importance of social influence, perceived interactivity, and perceived mobility to hedonic value is $100 \%, 85.8 \%$, and $93.3 \%$ respectively. It shows that perceived mobility is the most important factor affecting utilitarian value for continuous usage of the mobile government microblog, followed by perceived interactivity and social influence. On the other hand, social influence is the most significant factor influencing hedonic value for continuous usage of the mobile government microblog, followed by perceived mobility and perceived interactivity.

As shown in Table 8, the normalized importance of hedonic value and utilitarian value to continuance intention are $76.6 \%$ and $100 \%$. It shows that utilitarian value has better power to predict mobile government microblog continuance behaviors than hedonic value. 
Table 6. RMSE Values for ANN Model 3.

\begin{tabular}{ccc}
\hline & \multicolumn{2}{c}{$\begin{array}{c}\text { Model 3 Input neuron: UTV, HEV } \\
\text { Output neuron: COI }\end{array}$} \\
\hline Network & Training & Testing \\
1 & 0.2007 & 0.2049 \\
2 & 0.2049 & 0.1904 \\
3 & 0.2059 & 0.2028 \\
4 & 0.2072 & 0.2092 \\
5 & 0.1999 & 0.2070 \\
6 & 0.2001 & 0.2007 \\
7 & 0.1987 & 0.2034 \\
8 & 0.2004 & 0.2017 \\
9 & 0.2047 & 0.2029 \\
10 & 0.2064 & 0.2066 \\
Mean & 0.2029 & 0.2030 \\
Standard deviation & 0.0030 & 0.0049 \\
\hline
\end{tabular}

${ }^{*} \mathrm{HEV}=$ Hedonic value; $\mathrm{UTV}=$ Utilitarian value $\mathrm{COI}=$ Continuance intention .

Table 7. Sensitivity Analysis Based on Normalized Importance.

\begin{tabular}{ccccccc}
\hline & \multicolumn{3}{c}{$\begin{array}{c}\text { Model 1 Input neuron: SOI, PEI, PEM } \\
\text { Output neuron: UTV }\end{array}$} & \multicolumn{3}{c}{$\begin{array}{c}\text { Model 2 Input neuron: SOI, PEI, PEM } \\
\text { Output neuron: HEV }\end{array}$} \\
\hline Network & SOI & PEI & PEM & SOI & PEI & PEM \\
1 & 0.307 & 0.326 & 0.367 & 0.375 & 0.295 & 0.33 \\
2 & 0.348 & 0.325 & 0.326 & 0.388 & 0.242 & 0.369 \\
3 & 0.245 & 0.411 & 0.343 & 0.331 & 0.319 & 0.350 \\
4 & 0.361 & 0.309 & 0.330 & 0.323 & 0.322 & 0.355 \\
5 & 0.342 & 0.345 & 0.313 & 0.305 & 0.345 & 0.350 \\
6 & 0.269 & 0.324 & 0.407 & 0.393 & 0.267 & 0.340 \\
7 & 0.331 & 0.328 & 0.341 & 0.390 & 0.284 & 0.325 \\
8 & 0.308 & 0.306 & 0.385 & 0.317 & 0.327 & 0.356 \\
9 & 0.351 & 0.314 & 0.335 & 0.337 & 0.340 & 0.323 \\
10 & 0.302 & 0.339 & 0.359 & 0.385 & 0.301 & 0.314 \\
Mean & 0.316 & 0.333 & 0.351 & 0.354 & 0.304 & 0.341 \\
Normalized & 90.2 & 94.9 & 100 & 100 & 85.8 & 93.3 \\
Importance (\%) & & & & & & \\
\hline
\end{tabular}

* SOI = Social influence; $\mathrm{PEI}=$ perceived interactivity; $\mathrm{PEM}=$ perceived mobility.

Table 8. Sensitivity Analysis Based on Normalized Importance

\begin{tabular}{ccc}
\hline & $\begin{array}{r}\text { Model 3 Input neuron: UTV, HEV } \\
\text { Output neuron: COI }\end{array}$ \\
\hline Network & UTV & HEV \\
1 & 0.531 & 0.469 \\
2 & 0.558 & 0.442 \\
3 & 0.561 & 0.439 \\
4 & 0.619 & 0.381 \\
5 & 0.557 & 0.443 \\
6 & 0.527 & 0.473 \\
7 & 0.544 & 0.456 \\
8 & 0.537 & 0.463 \\
9 & 0.555 & 0.445 \\
10 & 0.672 & 0.328 \\
Mean & 0.566 & 0.434 \\
Normalized Importance $(\%)$ & 100 & 76.6 \\
\hline
\end{tabular}

${ }^{*} \mathrm{HEV}=$ Hedonic value; $\mathrm{UTV}=$ Utilitarian value; $\mathrm{COI}=$ Continuance intention . 


\section{Discussion}

\subsection{Interpretation of Results}

This study intends to understand the sustainability of a mobile government microblog by exploring the factors that affect citizens' intention to continue using the microblog services. Based on our proposed model and the data analysis, we will discuss several important findings.

First, in conformation with previous studies [33], the present study found that social influence significantly affects perceived value. This suggests that the influence from social relationships has a significant impact on citizens' continuous usage behavior. These social influences included influences from friends, colleagues, and important social circles. Thus, our study further validated the important role of social influence on continuance usage in the mobile government microblog context. In addition, the present study also found that media characteristics (i.e., perceived interactivity and perceived mobility) positively affect perceived value. This is consistent with previous research [48], which revealed that perceived interactivity significantly affects perceived value in the hotel website context. This suggests that increasing interactions on the government microblog can enhance users' perceived value. Similarly, consistent with the findings of previous studies [37], our study also found that perceived mobility positively affects perceived value. This suggests that the convenience and ubiquity of the mobile microblog can improve users' perceived value.

Second, the present study found that perceived value significantly influences citizens' continuance intention. This suggests that citizens' value perceptions play a vital role in determining their continuance intention. The link between perceived value and continuance intention has been validated in various research contexts [41,48]. In fact, both utilitarian value and hedonic value exert a significant effect on mobile government microblog continuance usage. This suggests that the reasons for citizens to continue using the microblog are the considerable utilitarian value and hedonic value, such as enjoyment and first-hand information obtained from their usage. This is the way that ensures the sustainable development of mobile government microblog services.

Finally, the artificial neural network was further used to analyze the importance of each significant factor. According to the results of the artificial neural networks analysis, perceived mobility is the most significant factor that affects utilitarian value, followed by perceived interactivity and social influence. Social influence is the most influencing factor on hedonic value, followed by perceived mobility and perceived interactivity. These findings are consistent with the results obtained from SEM, which further validated the different roles of social influence and media characteristics in determining utilitarian value and hedonic value. In addition, utilitarian value has a more important impact on mobile government microblog continuance behavior than hedonic value does, which highlights the critical role of citizens' utilitarian value in determining continuance usage of the mobile government microblog.

\subsection{Limitation and Future Work}

As with all empirical research, our study also has several limitations. First, the aim was to explore factors that affect mobile government microblog continuance usage. Our sample is collected from users at a single microblog platform (Sina Weibo) in China. Thus, further studies are encouraged to further test our results by using data collected from different microblog platforms in different countries.

Second, to capture the dynamic process of citizens' continuous use of the mobile government microblog, a longitudinal test conducted over a different time period would be a better research design. However, our cross-section design restricted the temporal analyses. Further studies are encouraged to employ a longitudinal design to test mobile government microblog continuance behavior.

Finally, the aim of this study was to examine the impact of sociality and media characteristics on citizens' perceived value and continuous use of the mobile government microblog. Other factors such as credibility [49] and public-private partnership [50] might also have impacts on citizens' mobile 
government microblog usage behaviors. Further studies are thus encouraged to examine the influences of credibility and public-private partnership on citizens' continuance behavior.

\section{Conclusions}

\subsection{Theoretical Implications}

First, this study applied the SOR framework in the emerging mobile government social media context, and validated the framework as a useful theoretical foundation to explain and predict citizens' mobile government microblog continuance behaviors. In addition, unlike the extant studies which mainly focused on the utilitarian value to explain mobile microblog usage, the present study explores citizens' mobile government microblog continuance by considering both utilitarian and hedonic value. The results of our study showed that in order to accurately explain and predict citizens' mobile government microblog continuance, both utilitarian value and hedonic value should be taken into consideration simultaneously.

Second, unlike previous studies which mainly adopted linear models such as SEM to explain mobile services usage, this study used a two-staged SEM-neural network method to explain and predict citizens' continuance behaviors. The significant factors obtained from SEM were used as inputs in neural network modeling to further rank the relative importance of these significant factors, which validated the results of SEM.

\subsection{Practical Implications}

The present study also has several practical implications for managers to improve the sustainable development of the mobile government microblog. First, microblog managers should pay close attention to the impact of social influence on government microblog usage, because this factor strongly and positively affects citizens' continuance intention. Specifically, social influence was found to be the most significant predictor affecting hedonic value when compared with the impacts of perceived mobility and perceived interactivity. The implication for mobile government microblog managers is obvious: they can enhance social influences of citizens' mobile government microblog usage to enhance users' hedonic value. For instance, they can include popular social media such as WeChat in their microblog platform to promote social influences.

Second, government agencies and mobile government microblog managers should also carefully consider the important role of mobility on shaping citizens' value perceptions. Specifically, perceived mobility is the most influencing factor that predicts utilitarian value when compared with the effects of social influence and perceived interactivity. Mobile government microblog managers should thus emphasize the convenience and ubiquity of using mobile government microblogs, as this will enhance citizens' utilitarian value perception. For instance, managers can provide location-based recommendation services and context-sensitive information which can add utilitarian value to citizens. In addition, perceived interactivity is beneficial to citizens' mobile government microblog continuance. Therefore, government agencies should do their best to enhance the interaction between the government and citizens. For instance, they can adopt an instant response strategy to interact with citizens.

Third, government agencies and mobile government microblog managers should observe the different roles of hedonic value and utilitarian value in determining citizens' mobile government microblog continuance behaviors. Specifically, the results of SEM-neural network analysis showed that utilitarian value exerts a relatively stronger impact on continuance behaviors than hedonic value. Therefore, government agencies which manage government microblogs should emphasize the utilitarian value of citizens' mobile government microblog continuance usage. Overall, mobile government microblog managers should enhance both hedonic and utilitarian value to encourage citizens' continuance usage. For instance, they should not only ensure that the information and services 
offered by the microblog are timely, accurate, and interesting, but also ensure that its layout is simple and clear.

Author Contributions: S.Y. conceived and designed the research; S.Y. and X.Z. collected data and analyzed the data; S.Y. and X.Z. wrote the paper; S.Y. reviewed and revised the paper.

Funding: This work was supported by the grants from the National Natural Science Foundation of China (71332001, 71472163, 71704153, 71701180), This work was also supported by the grants from the Humanity and Social Science foundation of Ministry of Education (18YJA630058), and Zhejiang Province Natural Science Foundation of China (LY18G020013, LY18G020014).

Acknowledgments: Thanks for the constructive comments provided by editors and four anonymous reviewers.

Conflicts of Interest: The authors declare no conflict of interest.

\section{Appendix A}

Table A1. Scales and items.

\begin{tabular}{|c|c|c|}
\hline Construct & Measure & Source \\
\hline \multirow{2}{*}{$\begin{array}{l}\text { Social influence } \\
\qquad(\mathrm{SOI})\end{array}$} & $\begin{array}{l}\text { 1. People who influence my behavior think that I should use Sina } \\
\text { government microblog APP. }\end{array}$ & \multirow[t]{2}{*}{ [43] } \\
\hline & $\begin{array}{l}\text { 2. My friends think that I should use Sina government microblog APP. } \\
\text { 3. People around me who use Sina government microblog APP have more } \\
\text { prestige than those who do not. } \\
\text { 4. People who use Sina government microblog APP have a high profile. }\end{array}$ & \\
\hline \multirow{3}{*}{$\begin{array}{l}\text { Perceived interactivity } \\
\qquad \text { (PEI) }\end{array}$} & $\begin{array}{l}\text { 1. Sina government microblog APP provides different ways to } \\
\text { communicate with others. }\end{array}$ & \multirow{3}{*}{ [44] } \\
\hline & $\begin{array}{l}\text { 2. I maintain close social relationships with some members in Sina } \\
\text { government microblog APP. }\end{array}$ & \\
\hline & $\begin{array}{l}\text { 3. I have frequent communication with some members in Sina government } \\
\text { microblog APP. }\end{array}$ & \\
\hline \multirow[t]{2}{*}{$\begin{array}{l}\text { perceived mobility } \\
\qquad(\text { PEM) }\end{array}$} & $\begin{array}{l}\text { 1. Sina government microblog APP would enable me to access government } \\
\text { information anytime, day or night. }\end{array}$ & \multirow[t]{2}{*}{ [40] } \\
\hline & $\begin{array}{l}\text { 2. Sina government microblog APP would enable me to obtain government } \\
\text { information from home, from the office, on the road, or at other locales. } \\
\text { 3. It would be convenient for me to get government information through } \\
\text { using Sina government microblog APP. }\end{array}$ & \\
\hline \multirow{2}{*}{$\begin{array}{l}\text { Hedonic value } \\
\qquad(\mathrm{HEV})\end{array}$} & $\begin{array}{l}\text { 1. The mobile government microblog would be ones that I enjoy. } \\
\text { 2. The mobile government microblog would make me feel good. }\end{array}$ & \multirow[t]{2}{*}{ [45] } \\
\hline & $\begin{array}{l}\text { 3. The mobile government microblog would be ones that I feel relaxed } \\
\text { about using. }\end{array}$ & \\
\hline \multirow{2}{*}{$\begin{array}{l}\text { Utilitarian value } \\
\qquad \text { (UTV) }\end{array}$} & $\begin{array}{l}\text { 1. Compared to the effort I need to put in, the use of the mobile } \\
\text { government microblog would be beneficial to me. }\end{array}$ & \multirow[t]{2}{*}{ [45] } \\
\hline & $\begin{array}{l}\text { 2. Compared to the time I need to spend, the use of the mobile government } \\
\text { microblog would be worthwhile to me. }\end{array}$ & \\
\hline \multirow{3}{*}{$\begin{array}{l}\text { Continuance intention } \\
\qquad(\mathrm{COI})\end{array}$} & $\begin{array}{l}\text { 1. I intend to continue using Sina government microblog APP to get related } \\
\text { information when I need to know government's services and policies. }\end{array}$ & \multirow{3}{*}[3,40]{} \\
\hline & $\begin{array}{l}\text { 2. I will consider continue using Sina government microblog APP to get } \\
\text { related information when I need to know other people's views to } \\
\text { the government. }\end{array}$ & \\
\hline & $\begin{array}{l}\text { 3. I will continue seeking government service through Sina government } \\
\text { microblog APP. }\end{array}$ & \\
\hline
\end{tabular}




\section{References}

1. Yang, S.; Hui, J.; Yao, J.; Chen, Y.; Wei, J. Perceived values on mobile GMS continuance: A perspective from perceived integration and interactivity. Comput. Hum. Behav. 2018, 89, 16-26. [CrossRef]

2. CNNIC. 42th Statistical Survey Report on Internet Development in China. Available online: http://www. cnnic.net.cn/ (accessed on 2 October 2018).

3. Zhao, L.; Lu, Y. Enhancing perceived interactivity through network externalities: An empirical study on micro-blogging service satisfaction and continuance intention. Decis. Support Syst. 2012, 53, 825-834. [CrossRef]

4. Guo, J.; Liu, Z.; Liu, Y. Key success factors for the launch of government social media platform: Identifying the formation mechanism of continuance intention. Comput. Hum. Behav. 2016, 55, 750-763. [CrossRef]

5. Panagiotopoulos, P.; Bigdeli, A.Z.; Sams, S. Citizen-government collaboration on social media: The case of Twitter in the 2011 riots in England. Gov. Inf. Q. 2014, 31, 349-357. [CrossRef]

6. Chen, Q.; Xu, X.; Cao, B.; Zhang, W. Social media policies as responses for social media affordances: The case of China. Gov. Inf. Q. 2016, 33, 313-324. [CrossRef]

7. Bertot, J.C.; Jaeger, P.T.; Grimes, J.M. Using ICTs to create a culture of transparency: E-government and social media as openness and anti-corruption tools for societies. Gov. Inf. Q. 2010, 27, 264-271. [CrossRef]

8. Jiang, C.; Zhao, W.; Sun, X.; Zhang, K.; Zheng, R.; Qu, W. The effects of the self and social identity on the intention to microblog: An extension of the theory of planned behavior. Comput. Hum. Behav. 2016, 64, 754-759. [CrossRef]

9. Kim, T.; Karatepe, O.; Lee, G.; Demiral, H. Do Gender and Prior Experience Moderate the Factors Influencing Attitude toward Using Social Media for Festival Attendance? Sustainability 2018, 10, 3509. [CrossRef]

10. Mehrabian, A.; Russell, J.A. An Approach to Environment Psychology; MIT: Cambridge, MA, USA, 1974.

11. Hew, T.S.; Leong, L.Y.; Ooi, K.B.; Chong, Y.L. Predicting Drivers of Mobile Entertainment Adoption: A Two-Stage SEM-Artificial-Neural-Network Analysis. J. Comput. Inf. Syst. 2016, 56, 352-370. [CrossRef]

12. Chong, Y.L. A two-staged SEM-neural network approach for understanding and predicting the determinants of m-commerce adoption. Expert Syst. Appl. 2013, 40, 1240-1247. [CrossRef]

13. Arpaci, I. A hybrid modeling approach for predicting the educational use of mobile cloud computing services in higher education. Comput. Hum. Behav. 2019, 90, 181-187. [CrossRef]

14. Liébana-Cabanillas, F.; Marinković, V.; Kalinić, Z. A SEM-neural network approach for predicting antecedents of m-commerce acceptance. Int. J. Inf. Manag. 2017, 37, 14-24. [CrossRef]

15. Sharma, S.K. Integrating cognitive antecedents into TAM to explain mobile banking behavioral intention: A SEM-neural network modeling. Inf. Syst. Front. 2017, 1-13. [CrossRef]

16. Liu, W.; Hu, G.; Tang, L.; Wang, Y. China's global growth in social science research: Uncovering evidence from bibliometric analyses of SSCI publications (1978-2013). J. Informetr. 2015, 9, 555-569. [CrossRef]

17. Liu, W.; Tang, L.; Gu, M.; Hu, G. Feature report on China: A bibliometric analysis of China-related articles. Scientometrics 2015, 102, 1-15. [CrossRef]

18. Kandampully, J.; Zhang, T.T.; Bilgihan, A. Customer loyalty: A review and future directions with a special focus on the hospitality industry. Int. J. Contemp. Hosp. Manag. 2015, 27, 379-414. [CrossRef]

19. Steen Møller, M.; Stahl Olafsson, A. The Use of E-Tools to Engage Citizens in Urban Green Infrastructure Governance: Where Do We Stand and Where Are We Going? Sustainability 2018, 10, 3513. [CrossRef]

20. Hens, L. Paul James: Urban sustainability in theory and practice: Circles of sustainability. Environ. Dev. Sustain. 2015, 17, 1-2. [CrossRef]

21. Kim, G.J.; Lee, H.; Son, S.M. A Study on Microblog Service Continuous Use Intention: Focusing on Influence. J. Inf. Syst. 2014, 23, 73-91.

22. Shareef, M.A.; Kumar, V.; Dwivedi, Y.K.; Kumar, U. Service delivery through mobile-government (mGov): Driving factors and cultural impacts. Inf. Syst. Front. 2016, 18, 315-332. [CrossRef]

23. Islam, J.U.; Rahman, Z. The impact of online brand community characteristics on customer engagement: An application of Stimulus-Organism-Response paradigm. Telemat. Inform. 2017, 34, 96-109. [CrossRef]

24. Babin, B.J.; Darden, W.R.; Griffin, M. Work and/or Fun: Measuring Hedonic and Utilitarian Shopping Value. J. Consum. Res. 1994, 20, 644-656. [CrossRef]

25. Overby, J.W.; Lee, E.-J. The effects of utilitarian and hedonic online shopping value on consumer preference and intentions. J. Bus. Res. 2006, 59, 1160-1166. [CrossRef] 
26. Batra, R.; Ahtola, O.T. Measuring the Hedonic and Utilitarian Sources of Consumer Attitudes. Mark. Lett. 1991, 2, 159-170. [CrossRef]

27. Yang, K.; Lee, H.J. Gender differences in using mobile data services: Utilitarian and hedonic value approaches. J. Res. Interact. Mark. 2013, 4, 142-156. [CrossRef]

28. Anderson, K.C.; Knight, D.K.; Pookulangara, S.; Josiam, B. Influence of hedonic and utilitarian motivations on retailer loyalty and purchase intention: A facebook perspective. J. Retail. Consum. Serv. 2014, 21, 773-779. [CrossRef]

29. Bitner, M.J. Servicescapes: The Impact of Physical Surroundings on Customers and Employees. J. Mark. 1992, 56, 57-71. [CrossRef]

30. Yang, S.; Lu, Y.; Gupta, S.; Cao, Y.; Zhang, R. Mobile payment services adoption across time: An empirical study of the effects of behavioral beliefs, social influences, and personal traits. Comput. Hum. Behav. 2012, 28, 129-142. [CrossRef]

31. Karahanna, E.; Straub, D.W.; Chervany, N.L. Information technology adoption across time: A cross-sectional comparison of pre-adoption and post-adoption beliefs. MIS Q. 1999, 23, 183-213. [CrossRef]

32. Ratten, V.; Khosrow-Pour, M. The Development of Social E-Enterprises, Mobile Communication and Social Networks: A Social Cognitive Perspective of Technological Innovation. J. Electron. Commer. Organ. 2013, 11, 68-77. [CrossRef]

33. Hong, S.J.; Tam, K.Y. Understanding the Adoption of Multipurpose Information Appliances: The Case of Mobile Data Services. Inf. Syst. Res. 2006, 17, 162-179. [CrossRef]

34. Thorson, K.S.; Rodgers, S. Relationships between Blogs as EWOM and Interactivity, Perceived Interactivity, and Parasocial Interaction. J. Interact. Advert. 2006, 6, 5-44. [CrossRef]

35. Yang, S.; Liu, Y.; Wei, J. Social capital on mobile SNS addiction: A perspective from online and offline channel integrations. Internet Res. 2016, 26, 982-1000. [CrossRef]

36. Dolen, W.M.V.; Dabholkar, P.A.; Ruyter, K.D. Satisfaction with Online Commercial Group Chat: The Influence of Perceived Technology Attributes, Chat Group Characteristics, and Advisor Communication Style. J. Retail. 2007, 83, 339-358. [CrossRef]

37. Kesari, B.; Atulkar, S. Satisfaction of mall shoppers: A study on perceived utilitarian and hedonic shopping values. J. Retail. Consum. Serv. 2016, 31, 22-31. [CrossRef]

38. Mallat, N.; Rossi, M.; Tuunainen, V.; Öörni, A. The impact of use context on mobile services acceptance: The case of mobile ticketing. Inf. Manag. 2009, 46, 190-195. [CrossRef]

39. Torkzadeh, G.; Dhillon, G. Measuring Factors that Influence the Success of Internet Commerce. Inf. Syst. Res. 2002, 13, 187-204. [CrossRef]

40. Venkatesh, V.; Thong, J.Y.L.; Chan, F.K.Y.; Hu, P.J.H. Managing Citizens' Uncertainty in E-Government Services: The Mediating and Moderating Roles of Transparency and Trust. Inf. Syst. Res. 2016, 27, 87-111. [CrossRef]

41. Liu, Y.; Li, H.; Kostakos, V.; Goncalves, J.; Hosio, S.; Hu, F. An empirical investigation of mobile government adoption in rural China: A case study in Zhejiang province. Gov. Inf. Q. 2014, 31, 432-442. [CrossRef]

42. Kim, Y.H.; Dan, J.K.; Wachter, K. A study of mobile user engagement (MoEN): Engagement motivations, perceived value, satisfaction, and continued engagement intention. Decis. Support Syst. 2013, 56, 361-370. [CrossRef]

43. Lu, J.; Yao, J.E.; Yu, C.-S. Personal innovativeness, social influences and adoption of wireless Internet services via mobile technology. J. Strat. Inf. Syst. 2005, 14, 245-268. [CrossRef]

44. Wang, E.S.; Wang, M.C. Social support and social interaction ties on internet addiction: Integrating online and offline contexts. Cyberpsychol. Behav. Soc. Netw. 2013, 16, 843-849. [CrossRef] [PubMed]

45. Kim, B.; Han, I. The role of utilitarian and hedonic values and their antecedents in a mobile data service environment. Expert Syst. Appl. 2011, 38, 2311-2318. [CrossRef]

46. Anderson, J.C.; Gerbing, D.W. Structural equation modeling in practice: A review and recommended two-step approach. Psychol. Bull. 1988, 103, 411-423. [CrossRef]

47. Bagozzi, R.P.; Yi, Y. On the evaluation of structural equation models. J. Acad. Market. Sci. 1988, 16, 74-94. [CrossRef]

48. Abdullah, D.; Jayaraman, K.; Kamal, S.B.M. A Conceptual Model of Interactive Hotel Website: The Role of Perceived Website Interactivity and Customer Perceived Value toward Website Revisit Intention. Procedia Econ. Finance 2016, 37, 170-175. [CrossRef] 
49. Chen, X.; Zhang, X. How Environmental Uncertainty Moderates the Effect of Relative Advantage and Perceived Credibility on the Adoption of Mobile Health Services by Chinese Organizations in the Big Data Era. Int. J. Telemed. Appl. 2016, 2016, 3618402. [CrossRef]

50. Kim, H.J. Multi-Stakeholders in Public and Cultural Diplomacies as Seen through the Lens of Public-Private Partnerships: A Comparative Case Study of Germany and South Korea. J. Contemp. East. Asia 2018, 17, 68-93.

(C) 2018 by the authors. Licensee MDPI, Basel, Switzerland. This article is an open access article distributed under the terms and conditions of the Creative Commons Attribution (CC BY) license (http://creativecommons.org/licenses/by/4.0/). 